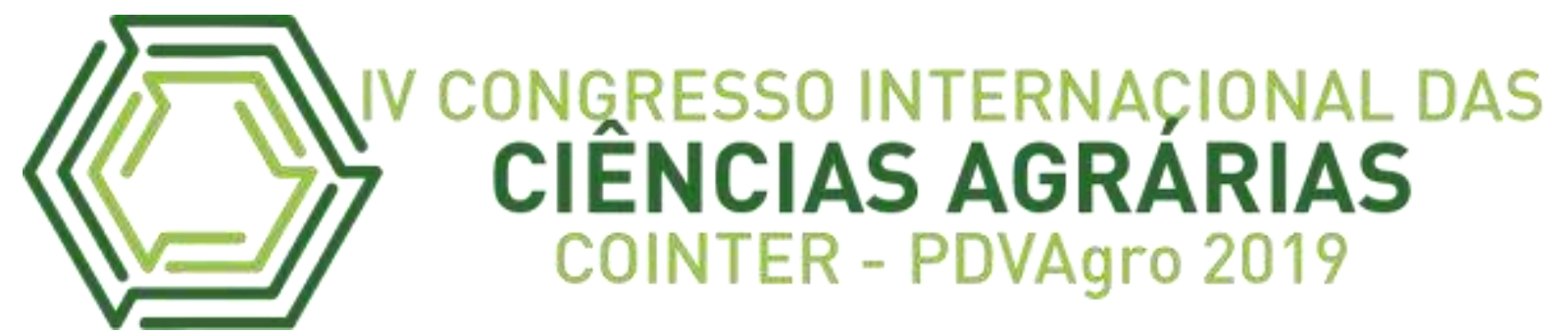

\title{
QUALIDADE DO CARVÃO VEGETAL PRODUZIDO EM FORNO CAIEIRA NO MUNICÍPIO DE OEIRAS DO PARÁ
}

\section{CALIDAD DEL CARBÓN VEGETAL PRODUCIDO EN EL HORNO CAIEIRA EN LA CIUDAD DE OEIRAS DE PARÁ}

\section{QUALITY OF VEGETABLE CHARCOAL PRODUCED IN CAIEIRA OVEN IN THE CITY OF OEIRAS OF PARÁ}

\author{
Apresentação: Comunicação Oral
}

\begin{abstract}
Roberta Marselle Santos Rodrigues ${ }^{1}$; Lucas Belém Tavares ${ }^{2}$; André Luiz da Silva Athaide ${ }^{3}$; Gabriel Marques Mercês ${ }^{4}$; Michel Douglas Roque Lima ${ }^{5}$
\end{abstract}

DOI: https://doi.org/10.31692/2526-7701.IVCOINTERPDVAgro.2019.0180

\begin{abstract}
Resumo
O Brasil é o maior consumidor e produtor de carvão vegetal do mundo, responsável por quase $80 \%$ do consumo deste material pela indústria siderúrgica. Apesar de muitos trabalhos serem produzidos sobre a biomassa energética do carvão, uma pequena parcela de trabalhos é destinada a questão da qualidade deste material, onde se encontra basicamente a importância, pois são a partir destas análises que são estabelecidas ou não as recomendações de uso destes produtos. Assim, o presente trabalho faz levantamentos de teores qualitativos à cerca de um carvão vegetal produzido no município de Oeiras do Pará, fabricado com o sistema de Caieira, sendo a madeira produto do resíduo da cultura de corte e queima. Analisar a qualidade do carvão. Foi realizada no Laboratório de Tecnologia de Produtos Florestais localizado na Universidade Federal Rural da Amazônia, no Campus Belém. Utilizou-se as técnicas de Tamboramento; Teor de Umidade; Teor de Materiais Voláteis; Teor de Cinzas; Teor de Carbono Fixo. O carvão oriundo do município de Oeiras tem umidade 4,88 \% $( \pm 1,16)$; teor de materiais voláteis $26,83 \%( \pm 4,43)$; teor de carbono fixo $68,80 \%( \pm 4,65)$; teor de cinzas $4,38 \%$ $( \pm 0,22)$, poder calorífero de $6.805( \pm 225,9)$. Sendo teores Fisico-quimicos significantes diferenças quando comparados a carvões de marcas já consolidadas no mercado, e apresar da cidade não possui um processamento industrial de carvão vegetal um possível investimento para gerar um bom carvão é preciso aperfeiçoar o padrão do produto e se tornar comercialmente competitivo, a fabricação pode aprimorar com o devido investimento em melhorias nos quesitos como tecnologia e processo de fabricação.
\end{abstract}

Palavras-Chave: Carvão vegetal, Teores físico-quimicos, Poder Calorífero, Oeiras do Pará.

\footnotetext{
${ }^{1}$ Graduanda em Engenharia Agronômica, UFRA, roberta.ms.rodrigues0@gmail.com

2 Graduando em Engenharia Florestal, UFRA, lucasbelemtavares@gmail.com

3 Graduando em Engenharia Florestal, UFRA, andreathaide19@gmail.com

4 Graduando em Engenharia Florestal, UFRA, marquesgabriel.agro@gmail.com

5 Mestrando em Ciências Florestais, UFRA, lima_florestal@outlook.com
} 


\title{
Resumen
}

Brasil es el mayor consumidor y productor de carbón vegetal del mundo, y representa casi el $80 \%$ del consumo de este material por parte de la industria del acero. Aunque muchos trabajos se producen sobre la biomasa energética del carbón, una pequeña parte del trabajo está dirigida a la calidad de este material, donde es básicamente la importancia, porque es a partir de estos análisis que se establecen o no las recomendaciones para su uso. productos Por lo tanto, el presente trabajo realiza encuestas cualitativas sobre un carbón producido en el municipio de Oeiras do Pará, fabricado con el sistema Caieira, y la madera es el producto del residuo de la cultura de corte y quema. Analizar la calidad del carbón. Se llevó a cabo en el Laboratorio de Tecnología de Productos Forestales ubicado en la Universidad Federal Rural de Amazonia, en el Campus de Belém, y se utilizaron las técnicas de tambor; Contenido de humedad; Contenido de material volátil; Contenido de ceniza; Contenido de carbono fijo. El carbón del municipio de Oeiras tiene una humedad del 4,88\% $( \pm 1,16)$; contenido de materiales volátiles $26.83 \%$ ( \pm 4.43 ); contenido de carbono fijo $68.80 \%$ ( \pm 4.65$)$; contenido de cenizas $4.38 \%$ ( \pm 0.22$)$, valor calorífico de 6.805 ( \pm 225.9$)$. Al ser diferencias fisicoquímicas significativas en comparación con los carbones de las marcas ya consolidadas en el mercado, y la ciudad no tiene procesamiento industrial de carbón, una posible inversión para generar un buen carbón es necesario para mejorar el estándar del producto y ser comercialmente competitivo, la fabricación puede mejorar invirtiendo en mejoras en la tecnología y el proceso de fabricación.

Palabras Clave: Carbón vegetal, contenido físico-químico, valor calorífico, Oeiras do Pará.

\begin{abstract}
Brazil is the largest consumer and producer of charcoal in the world, accounting for almost $80 \%$ of the consumption of this material by the steel industry. Although many works are produced on the energy biomass of coal, a small portion of the work is aimed at the quality of this material, where it is basically the importance, because it is from these analyzes that are established or not the recommendations for their use. products. Thus, the present work makes qualitative surveys about a charcoal produced in the municipality of Oeiras do Pará, manufactured with the Caieira system, and the wood is the product of the residue of cutting and burning culture. Analyze the quality of coal. It was held at the Forest Products Technology Laboratory located at the Federal Rural University of Amazonia, at the Belém Campus. The techniques of Drumming were used; Moisture content; Volatile Material Content; Ash content; Fixed Carbon Content. The coal from the municipality of Oeiras has a humidity of $4.88 \%( \pm 1.16)$; volatile materials content $26.83 \%( \pm 4.43)$; fixed carbon content $68.80 \%$ ( \pm 4.65$)$; ash content $4.38 \%$ ( \pm 0.22 ), calorific value of 6.805 ( \pm 225.9 ). Being significant physicochemical differences when compared to charcoals of brands already consolidated in the market, and the city has no industrial processing of charcoal a possible investment to generate a good coal it is necessary to improve the standard of the product and become commercially competitive, manufacturing can improve by investing in improvements in technology and manufacturing process.
\end{abstract}

Keywords: Charcoal, Physical chemical contents, calorific value, Oeiras do Pará. 


\section{Introdução}

Desde a antiguidade, o homem vem utilizando o fogo, a tração animal e a energia gerada dos ventos ou das quedas d'água para atender algumas de suas necessidades básicas. $\mathrm{O}$ modelo tecnológico, adaptado ao mundo moderno, apoiou-se muito cedo no emprego preferencial de energia proveniente dos combustíveis, tais como o próprio carvão (SOARES et al., 2006).

O Brasil é o maior produtor e consumidor de carvão vegetal do mundo. Este carvão é destinado, principalmente, ao setor siderúrgico. Cerca de aproximadamente $77 \%$ do carvão produzido é consumido na indústria siderúrgica na redução do minério de ferro a ferro-gusa (BRASIL, 2010).

O carvão vegetal também conhecido como biocarvão é um material sólido rico em carbono preto resultante do processo de pirólise, decomposição térmica de resíduos orgânicos a elevadas temperaturas e em baixa concentração de oxigênio (LIMA, 2016).

A Amazônia é uma das principais regiões produtoras para esses fins. Nas últimas décadas, o setor florestal madeireiro esteve no centro das discussões de políticas públicas por ser uma atividade catalisadora do processo de ocupação predatória (VERÍSSIMO; PEREIRA, 2015). Até 1994, técnicas de manejo florestal eram praticamente inexistentes na Amazônia, entretanto, houve avanços nas técnicas deste manejo, melhoria da fiscalização ambiental e aperfeiçoamento do marco regulatório com destaque para a lei de concessões florestais ou lei de gestão de florestas públicas a partir de 2006 (LEI 11.284/2006).

O interesse pela utilização de espécies madeireiras para produção de energia e carvão vegetal vem aumentando significativamente em decorrência da necessidade da busca de melhores rendimentos de produção e melhores propriedades da madeira destinada a esses fins. Já é grande o número de pesquisas desenvolvidas neste campo, havendo um somatório considerável de fatores preconizados como fundamentais para análise (BRITO et al., 1983).

No Pará é crescente este tipo de atividade, especialmente no município de Oeiras. O território da cidade de Oeiras do Pará é localizado entre as Zonas da Ilha do Marajó e o Tocantins, na macrorregião de Cametá (IBGE, 2016), o município abrange uma área de 385.249,8846 Ha, sendo que 21,66\% dessa equivalem à Reserva Extrativista Arióca Pruanâ (REAP) que interliga uma área de proteção entre os três maiores rios (rio Oeiras, Arióca e 
Pruanâ), que cortam o município (JUNIOR et al., 2013).

Em 2010, o município obteve densidade demográfica de 7,42 Hab/Km² (IBGE, 2015), de modo geral, a economia no município recai sob a prefeitura municipal, as atividades extrativistas (madeira, açaí, palmito, pesca) e uma pequena parte na agricultura familiar de subsistência (produção de farinha de mandioca); o comércio é fraco, e o empresariado quase inexistente (AMARO et al., 2016).

Alguns empreendimentos florestais no município foram mal sucedidos, possivelmente por falta de estrutura como o caso de uma grande serraria que seria instalada aos fundos da cidade. A primeira parte do projeto chegou a sair do papel e até hoje resiste ao tempo. O principal motivo pelo qual o projeto não teve êxito, foi pela incapacidade da cidade na obtenção de energia elétrica para o funcionamento das máquinas.

Ao longo do tempo a rede comercial de Oeiras vem sofrendo modificações. Além do extrativismo outras atividades vieram ocupando espaço no mercado da cidade como a agricultura de corte e queima, e o aproveitamento da cuivara (resíduo não carbonizado da roça) para a produção de carvão vegetal. Considerando a importância de produção de biomassa e do carvão vegetal como fonte de economia para este local, o objetivo deste trabalho é fazer uma análise das propriedades físico-química do carvão vegetal comercializado no município de Oeiras do Pará.

\section{Fundamentação Teórica}

Segundo o IMAZON (2010) cerca de $20 \%$ do resíduo proveniente do processamento da medira é aproveitado na produção de carvão vegetal, são mais de 1,6 milhões de metros cúbicos de madeira aproveitada como bioenergia.

$\mathrm{Na}$ Amazônia segundo Letini et al (2005) mais de 8,4 milhões de metros cúbicos de madeiras em toras não foram aproveitadas pela indústria madeira da região, desperdiçando um potencial é econômico de grande viabilidade economia que poderia está levando renda e qualidade de vida para a população.

\section{Metodologia}

Área de estudo foi o brasileiro de Oeiras do Pará (Figura 1), localizado no norte do Estado do Pará, a uma latitude $02^{\circ} 00^{\prime} 11^{\prime \prime}$ sul e a uma longitude $49^{\circ} 51^{\prime} 16^{\prime \prime}$ oeste, estando a uma altitude de 2 metros. Na microrregião de Cametá, limitando-se ao norte com o rio Pará, a 
oeste com Bagre, ao sul com os municípios de Mocajuba e Baião e a leste com Limoeiro do Ajuru e Cametá.

Figura 1. Localização do município de Oeiras, estado do Pará.

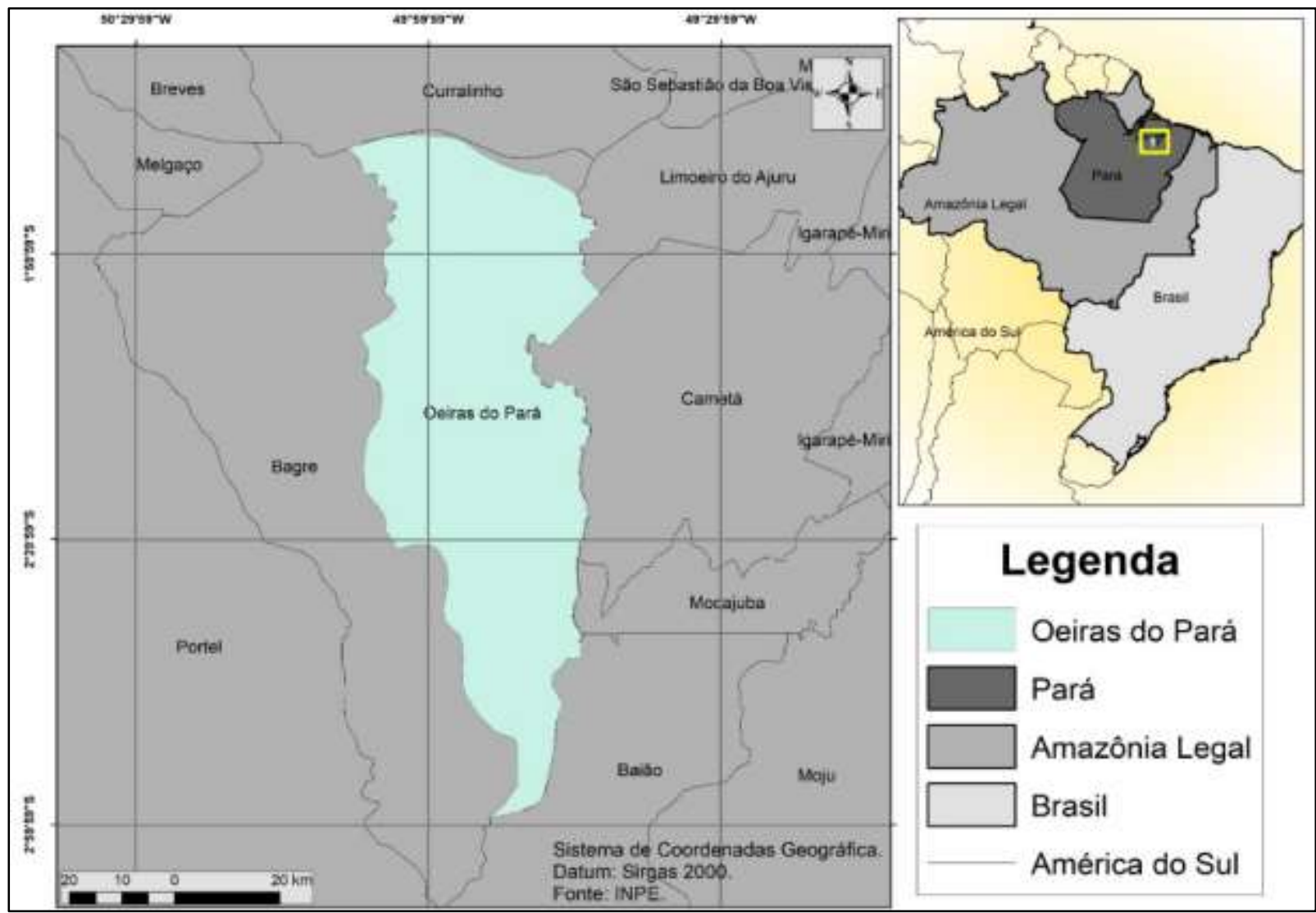

Fonte: Própria (2019).

O carvão vegetal utilizado foi uma saca de $16 \mathrm{~kg}$, sendo que foram comprados na feira da cidade de Oeiras do Pará em $2 \mathrm{~kg}$ de 8 interiores diferentes, todos proveniente da técnica de caieira, que é o forno artesanal que no máximo de sofisticação é um buraco no chão que suas paredes são armadas com os próprios tijolos a serem cozidos, quando não é só um buraco no chão com mais ou menos um metro e meio de largura e dois metros de comprimento e com sessenta a oitenta sentimentos de profundidade, onde se arruma as galhos e troncos finos de árvores, na sua maioria resíduos da cuivara do roçado, até a superfície é colocado folhas de palmeira do inajás (Attalea maripa), e cobrindo com a mesma terra que foi tirado do buraco, deixando o rabo quente onde coloca-se o fogo (combustão inicial).

As analises físicas e químicas foram realizados no Laboratório de Tecnologia de Produtos Florestais localizado na Universidade Federal Rural da Amazônia, no Campus Belém. Para determinar a qualidade do carvão vegetal utilizou-se de algumas técnicas, sendo 
essas o Tamboramento; Teor de Umidade; Teor de Materiais Voláteis; Teor de Cinzas; Teor de Carbono Fixo.

\section{Tamboramento}

O tamboramento do carvão, é o processo pelo qual o carvão passa por um tratamento de choque mecânicos em que se perde a massa das superfícies das peças de carvão, assim o processo tem a capacidade de verificar a resistência e a friabilidade do mesmo.

Foram pesadas em balança digital 5 bandejas com aproximadamente $500 \mathrm{~g}$ de carvão em cada corpo de prova, e colocadas em seguida no tambor, as 5 repetições, em um tempo de 15 minutos para cada bandeja dentro da máquina girando, e depois era retirado só o material sólido de dentro e pesado novamente (Figura 2).

Figura 2. Máquina de Tamboramento.

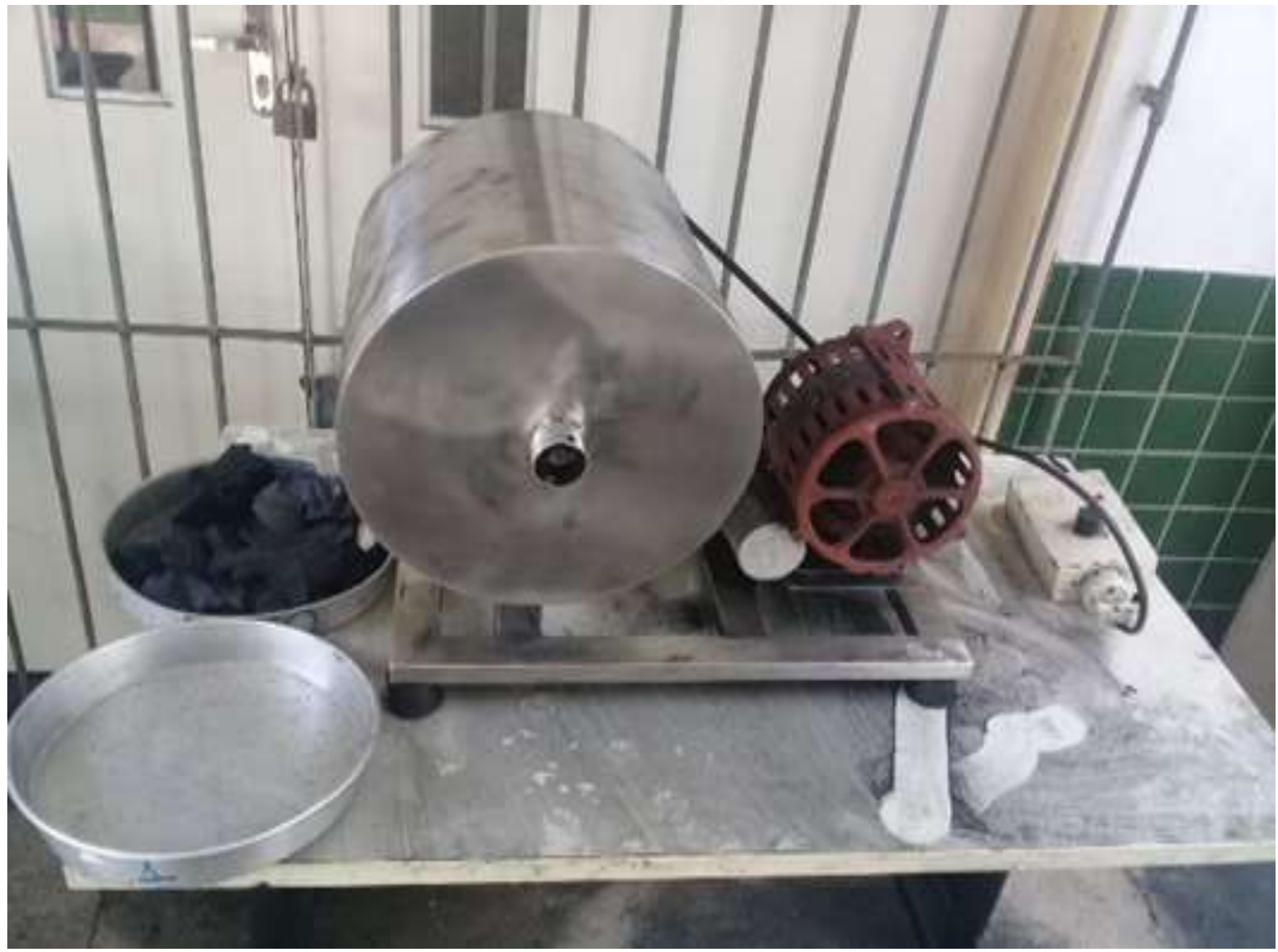

Fonte: Própria (2019).

O pó que restou, foi passado em uma peneira com 25 mesh e retido em 45 mesh. Geralmente essas partículas são obtidas por meio de processo mecânico, podendo, no entanto, 
ser obtido manualmente com uso de gral. Para poder ser determinado as análises químicas, que se referem à determinação dos teores de umidade (TU), materiais voláteis (TMV), cinzas (TCI) e carbono fixo (TCF) contidos no carvão.

\section{Teor de Umidade}

O material usado foi uma balança; placa de petri; carvão moído e peneirado (10g), 3 placas de petri seca a $105^{\circ} \mathrm{C}$. Pesado as placas em uma balança e colocado em cada uma com cerca de $3 \mathrm{~g}$ de carvão peneirado correspondentes a $\mathrm{P}(\mathrm{cvU} \%)$. Em seguida as placas foram colocadas em uma estufa com temperatura controlada a $105^{\circ} \mathrm{C}$, e após 24 horas, pesados obtendo-se o $\mathrm{P}(\mathrm{cv0} \%)$.

Calculou-se o TU através da seguinte fórmula:

Onde:

$$
T U=P(c v U-P(c v 0 \% / P(c v U) x 100
$$

$\mathrm{P}(\mathrm{CVu} \%)$ - peso do carvão úmido, em gamas.

$\mathrm{P}(\mathrm{cv0 \% )}$ - peso do carvão completamente seco, em gamas.

\section{Teor de Materiais Voláteis}

Foi utilizado uma balança; cadinhos com tampas; espátulas; carvão moído e peneirado (20g). Colocado 3 cadinhos com tampas secos a $105^{\circ} \mathrm{C}$, pesados os 3 cadinhos com tampas (1P(cad), 2P(cad), 3P(cad)) na balança e colocados em cada um 2 a $3 \mathrm{~g}$ de carvão moído, absolutamente seco, anotando-se os pesos 1P(cv0\%), 2P(cv0\%), 3P(cv0\%). Depois, foram colocados os cadinhos com tampas para pré-aquecer em uma estufa a $250^{\circ} \mathrm{C}$, durante 5 minutos e, $\operatorname{logo}$ após introduzidos na mufla aquecida a $950^{\circ} \mathrm{C}$, deixando por 6 minutos. O cadinho deve estar sempre com a tampa bem fechada para evitar a combustão do carvão. Esgotado o tempo, os cadinhos devem ser retirados, com cuidado, da mufla e deixados em um dessecador para esfriamento (1 hora). Pesados novamente os cadinhos após a calcinação do carvão a $950^{\circ} \mathrm{C}$, anotando-se: $1 \mathrm{P}\left(\mathrm{c} 950^{\circ} \mathrm{C}\right), 2 \mathrm{P}\left(\mathrm{c} 950^{\circ} \mathrm{C}\right), 3 \mathrm{P}\left(\mathrm{c} 950^{\circ} \mathrm{C}\right)$.

Para ser calculado o TMV foi usada a seguinte fórmula:

$$
T M V=P(c v 0 \%)-P\left(c 950^{\circ} C\right) / P(\operatorname{cv} 9 \%) X 100
$$

Onde:

$\mathrm{P}(\mathrm{cv0 \%})$ - peso do carvão absolutamente seco em gama.

$\mathrm{P}\left(\mathrm{c} 950^{\circ} \mathrm{C}\right)$ - peso do carvão calcinado a $950^{\circ} \mathrm{C}$ em gama. 


\section{Teor de Cinzas}

O material usado foi uma balança; cadinhos; carvão peneirado (10g). Preparou-se 3 cadinhos secos a $105^{\circ} \mathrm{C}$, pesou-se os cadinhos na balança, anotando-se o peso de $1 \mathrm{P}(\mathrm{Cad})$, $2 \mathrm{P}(\mathrm{Cad})$, e $3 \mathrm{P}(\mathrm{Cad})$, depois foi pesado em cada cadinho de 2 a $3 \mathrm{~g}$ de carvão moído absolutamente seco (0\%). Colocou-se os cadinhos sem tampas com o carvão, submetendo-se a combustão completa a $750^{\circ} \mathrm{C}$ durante 6 horas. Esgotado o tempo, os cadinhos foram retirados, com muito cuidado, da mufla, e deixados em um dessecador para esfriamento (10 minutos). Pesados os cadinhos após a combustão, anotando-se: $1 \mathrm{P}\left(\mathrm{c} 750^{\circ} \mathrm{C}\right), 2 \mathrm{P}\left(\mathrm{c} 750^{\circ} \mathrm{C}\right)$, $3 \mathrm{P}\left(\mathrm{c} 750^{\circ} \mathrm{C}\right)$.

Foi calculado o TCI através da seguinte fórmula:

$$
\text { TCI }=(\text { Pcinzas } / \text { Pcv0\%) X } 100
$$

Onde:

$\mathrm{P}(\mathrm{CV} 0 \%)$ - peso do carvão absolutamente seco, em gama.

P(cinzas) - peso das cinzas após a completa oxidação do carvão em gama.

5. Teor de Carbono Fixo

Este Teor é determinado à base úmida e base seca, através das seguintes fórmulas:

$$
\begin{gathered}
\text { TCF }(\text { b.u })=100-(T U+T M V+T C I * \text { base úmida }) \\
\text { TCF }(\text { b.s })=100-(T M V+T C I * \text { base seca })
\end{gathered}
$$

6. Densidade do carvão

6.1. Densidade Aparente Básica. 
Nesse contexto, foi realizado outro procedimento para se determinar a densidade do carvão vegetal, sendo a primeira densidade aparente básica $\left(\mathrm{g} / \mathrm{cm}^{3}\right)$. Utilizou-se amostras de carvão (pedaços retirados aleatoriamente do lote). Como material, usou-se balança, placa de petri, bomba a vácuo e estufa elétrica. Para o preparo do corpo de prova- CP foi selecionado 5 corpos de prova com o mínimo possível de trincamentos ou rachaduras com dimensões de 2x2x3 cm (Figura 3A). Não havendo necessidade de forma regular. Em seguida, foram colocados os CPs para saturar em uma bomba a vácuo, determinando o volume de cada um dos CPs saturado [(V(cp-saturado))] (Figura 3B), pelo método de pesagem (princípio de Arquimedes), depois os CPs foram deixados em uma estufa controlada a $105^{\circ} \mathrm{C}$, até atingir o peso constante em três pesagens consecutivas, peso esse que corresponderá ao estado anidro do carvão $\mathrm{P}(0 \%)$, isto é, $0 \%$ de umidade.

Figura 3. Corpos de prova com o mínimo possível de trincamentos ou rachaduras com dimensões de $2 \times 2 \times 3 \mathrm{~cm}$.

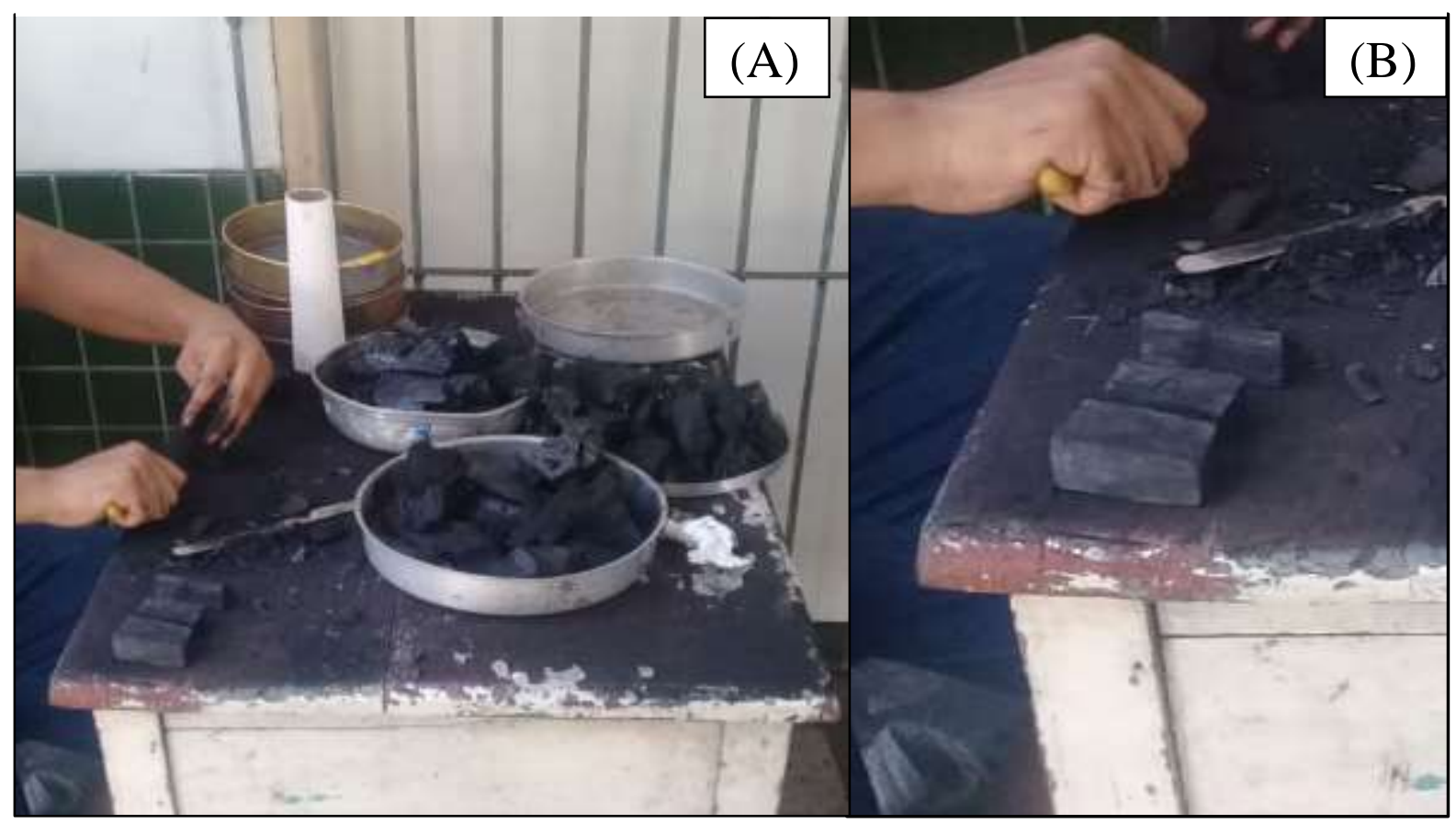

Fonte: Própria (2019)

Calculou-se a densidade com a seguinte equação:

$$
\boldsymbol{D A}(\text { básica })=P(0 \%) / V(\text { saturado })
$$

Onde:

DA(básica) - densidade aparente básica $\mathrm{g} / \mathrm{cm}^{3}$

$\mathrm{P}(0 \%)$ - peso do $\mathrm{CP}$ a $0 \%$ de umidade, $\mathrm{g}$.

$\mathrm{V}$ (saturado) - volume do CP saturado, $\mathrm{cm}^{3}$. 


\subsection{Densidade a Granel.}

Usou-se amostras de carvão (pedaços aleatoriamente do lote, tendo que ter o tamanho máximo de 7 x $7 \mathrm{~cm}$ de seção transversal e comprimento de $2 \mathrm{~cm}$. Utilizou-se um recipiente de volume interno conhecido (balde) e uma balança para pesagem do recipiente com o carvão, sendo colocado dentro do balde pedaços de carvão de forma aleatória até preenche-lo completamente. Depois foi pesado o recipiente mais o carvão para obtenção do peso do carvão a granel.

Calculou-se a densidade a granel com a seguinte equação:

$$
D(\text { carvão a granel })=P(\text { cva granel }) / V(\text { recipiente })
$$

Onde:

P(carvão a granel) - peso do carvão contido no recipiente, kg.

$\mathrm{V}($ recipiente $)$ - volume do recipiente, mdc.

O Volume mdc, significa metro de carvão que corresponde a quantidade de carvão contido em um recipiente de volume interno conhecido.

\section{Resultados e Discussão}

Quanto ao teor de friabilidade (Capacidade que o carvão tem de ser ou não transformado em pó devido à ação mecânica atributos de choques provocados durante o seu manuseio), de posse dos dados apresentados na tabela 1, é possível estabelecer que o tipo de carvão analisado possua um teor de friabilidade classificado como pouco friável com valor em média de $13,1 \%( \pm 6,07)$, visto que as Classes de classificação quanto a friabilidade são: Muito friável; Bastante friável; medianamente friável; pouco friável e Muito pouco friável, onde estas apresentam os respectivos valores de perda: Superior à 30\%; de 25 -29\%; de 15 - 24\%; de $10-14 \%$ e Inferior à $10 \%$.

Tabela 1. Teor de Friabilidade do Carvão Vegetal produzido no forno caieira. $\mathrm{PB}=$ Peso da bandeja; PI = Peso Inicial; Peso da Bandeja + Peso do Carvão; PCT = Peso líquido do carvão após o Tamboramento.

\begin{tabular}{rrrccc}
\hline Repetição & PB & PI(g) & PB+PC(g) & PCT(g) & Friabilidade (\%) \\
\hline $\mathbf{1}$ & 191 & 509 & 630 & 439 & 13,8 \\
$\mathbf{2}$ & 186 & 500 & 629 & 443 & 11,4 \\
$\mathbf{3}$ & 182 & 508 & 572 & 390 & 23,2 \\
\hline
\end{tabular}




\begin{tabular}{rrrrcc}
\hline $\mathbf{4}$ & 181 & 500 & 633 & 452 & 9,6 \\
$\mathbf{5}$ & 116 & 508 & 585 & 469 & 7,7 \\
Média & & & & & 13,1 \\
\hline
\end{tabular}

Fonte: Própria (2019)

A classificação do carvão como, pouco friável. Aspecto que garante uma boa qualidade do carvão em que apresenta resistência mecânica por atritos, que o exemplo é o atrito do próprio manuseado que acontece durante seu transporte.

Para a análise química imediata, alguns valores foram calculados para o carvão vegetal, feito no forno tipo caieira no município de Oeiras-PA. A pesquisa executada, obteve uma comparação a outras duas observações que contém valores médios de trabalho já realizado, um no estado de São Paulo que possui o "selo premium", cuja comercialização é feita no município de Alegue -SP (ROSA et al., 2012), e outro com um carvão vegetal proveniente de reflorestamento do gênero Eucalytus spp. também comercializado no estado de São Paulo e oriundo da cidade de Itapevá - SP (GARCIA et al., 2017).

Tabela 2.Valores médios dos teores de umidade, materiais voláteis, carbono fixo, cinzas e poder calorífico superior dos carvões vegetais analisados. $\mathrm{U}=$ umidade; $\mathrm{TMV}=$ teor de materiais voláteis; $\mathrm{TCF}=$ teor de carbono fixo; TCZ=teor de cinzas; $\mathrm{PCS}=$ poder calorífico superior.

\begin{tabular}{ccccccc}
\hline Classes & Estatística & U(\%) & TMV(\%) & TCF(\%) & TCZ(\%) & PCS (cal. $\left.\boldsymbol{g}^{\mathbf{- 1}}\right)$ \\
\hline 1.(Carvão Premium) & Média & 4,17 & 23,64 & 75,46 & 0,68 & 7432 \\
$\begin{array}{c}\text { 2.(Carvão de } \\
\text { Eucalyptus spp.) }\end{array}$ & Média & 5,19 & 15,53 & 83,67 & 1,42 & 7070 \\
3.(Carvão de Caieira) & Média & 4,88 & 26,83 & 68,80 & 4,38 & 6805 \\
\hline
\end{tabular}

Fonte: Própria (2019)

É possível reconhecer que o carvão comercializado no estado de São Paulo que possui o "selo premium", se trata de um carvão com alta qualidade, e possui os requisitos necessários para ser usado domesticamente, contém densidade média de 0,379 g.cm- ${ }^{3}$ quanto para a umidade de $4,17 \%$, são bons indicadores para tal uso. A densidade relativa aparente possui uma relação direta com a qualidade do carvão vegetal, ou seja, quanto maior a densidade do carvão vegetal, maior será o seu PCS, assim, maior a energia contida no material por unidade de massa, o que acarreta no maior rendimento do carvão. Já a umidade possui relação inversa com a qualidade do carvão, pois quanto maior a umidade, menor o rendimento gravimétrico 
da biomassa energética (Tabela 2).

Embora o desejado seja um baixo TMV para o consumo doméstico de carvão vegetal, visando assim, uma menor quantidade de substâncias tóxicas liberada durante o preparo de alimentos, sua ignição será dificultada pela quantidade dos materiais voláteis contidos nas amostras deste carvão (BRAHAN, 2002).

O Carvão de Eucalyptus spp produzido na cidade Itapevá - SP e comercializado na capital, a umidade apresenta alta para os parâmetros de uso doméstico, visto que a resolução No 40 (SÃO PAULO, 2015), estabelece uma umidade máxima de 5,0\%. Então, observa-se que este carvão não possui bons índices de umidade. Outros autores também detectaram altos teores de umidade em carvões comercializados no estado de Minas Gerais, o que demonstra que apesar de existirem padrões de qualidade, os produtores não demonstram muito interesse em obedecê-los, muitas vezes refletindo negativamente e causando insatisfação ao consumidor final.

Os teores de materiais voláteis se mostraram satisfatórios para o carvão de Eucalyptus spp, pois altos teores de materiais voláteis significam alta quantidade de fumaça gerada, baixa eficiência energética, além de proporcionar um maior consumo de carvão vegetal, neste caso quando comparado a bibliografia de referência para carvões feitos do Eucalipto, onde o teor máximo de matérias voláteis recomendado é de no máximo 23,6 \% (ROSA et al., 2012).

Para teores de carbono fixo, este carvão apresentou um valor satisfatório quando comparados aos valores de referência para carvões desta espécie, que giram em torno de $75 \%$, enquanto que as amostras desse carvão vegetal mostram uma média superior a $80 \%$, fator positivo para esta biomassa, em relação ao teor de cinzas, esta classe se apresentou com um bom desempenho, apesar de ter sido superior a 1,0\%, não ultrapassou o limite estabelecido de $1,73 \%$ utilizado para que o carvão possua bons índices de teores de cinza.

Já em relação ao PCS (Poder Calorífico Superior), o carvão proveniente do Eucalipto mostrou um desempenho satisfatório, apesar de ter sido inferior ao carvão considerado "premium" pelo estado de São Paulo, este também se mostrará adequado para o uso doméstico, pois liberará quantidade suficiente de energia para seu correto uso.

Se tratando do carvão de fornos que usam o sistema de caieiras e resíduos da prática de coivara no município de Oeiras do Pará, este sendo o material analisado pelos autores do presente trabalho, os resultados de uma forma geral se mostram inferiores aos demais analisados na sua maioria. A umidade é o único teor que pode ser considerado satisfatório 
para este material, com um valor médio de 4,88\% $( \pm 1,16)$, retrata um bom teor de umidade do mesmo. Quanto aos teores de materiais voláteis, este material apresentou um valor de 26,83\% $( \pm 4,43)$, não muito superior ao Carvão Premium, este por sua vez mostra uma porcentagem aceitável neste quesito.

O teor de cinzas talvez tenha sido o mais negativo em termos de qualidade deste material, com uma média superior a 4,0\% $( \pm 0,22)$, está demasiadamente distante do ideal para ser considerado bom para o uso doméstico. Porém, como trata-se de um carvão produzido artesanalmente, com ausência de rigores técnicos, e voltado basicamente para uma comercialização de subsistência, é coerente que este teor se apresente de forma elevada, e também apesar de ser um carvão do tipo pouco friável. Os teores de Carbono Fixo deste carvão se mostraram inferiores aos demais, apesar da falta de tecnologia para a produção desse carvão, o valor de $68,80 \%( \pm 4,65)$ mostra um carvão com um elevado potencial de carbono fixo, e que possivelmente fosse produzido com mais padrões qualitativos fatalmente apresentaria melhores resultados, não apenas neste quesito, bem como nos demais.

O Poder Calorifico Superior também foi registrado com o menor valor quando comparado aos demais carvões, com uma média de 6805 kcal kg-1 $( \pm 227,98)$, é um valor que apesar de ser potencialmente bom, não chega a ser considerado ideal para o uso doméstico, proporcionando assim uma alta demanda de carvão para combustão quando utilizado.

Tabela 3. Densidade a granel do carvão de Caieira comercializado na cidade de Oeiras do Pará.

\begin{tabular}{lcc}
\hline No da Repetição & Carvão & Densidade a granel $\left(\mathbf{k g} / \mathbf{m}^{\mathbf{3}}\right)$ \\
\hline $\mathbf{1}$ & 210,8 \\
\hline $\mathbf{2}$ & 209,5 \\
\hline $\mathbf{3}$ & 215,5 \\
\hline $\mathbf{4}$ & 250,6 \\
\hline $\mathbf{5}$ & 223,5 \\
\hline Média & 222
\end{tabular}

Fonte: Própria (2019)

Com base dos dados de densidade a granel obtidos do carvão vegetal (Tabela 3), e comparando aos dados de Gomes \& Oliveira (2015), onde o mesmo encontrou médias de densidade a granel para carvões vegetais de Pinus spp, Eucalyptus spp e Acácia Negra nos valores 181, 192 e $230\left(\mathrm{~kg} / \mathrm{m}^{3}\right)$ respectivamente, observa-se que o carvão do tipo caieira produzido no Município de Oeiras do Pará possui uma densidade a granel satisfatória, isso 
significa que também que ao ser embalado, este produto não possuirá muitos espaços vazios entre as peças de carvão, podendo assim transportar uma boa quantidade de carvão vegetal sem causar prejuízos ao consumidor.

\section{Conclusões}

O carvão oriundo do município de Oeiras tem umidade 4,88\% $( \pm 1,16)$; teor de materiais voláteis $26,83 \%( \pm 4,43)$; teor de carbono fixo $68,80 \%( \pm 4,65)$; teor de cinzas $4,38 \%$ $( \pm 0,22)$, poder calorífero de $6.805 \mathrm{kcal} \mathrm{kg}-1( \pm 225,9)$. Sendo teores Físico-químicos significantes diferenças quando comparados a carvões de marcas já consolidadas no mercado, e que, assim o carvão do município de Oeiras do Pará não gerando uma boa competitividade.

Contudo vale ressaltar que a friabilidade do carvão produzido em Oeiras ficou classificado como pouco friável com valor em média de $13,1 \%( \pm 6,07)$, o poder calorifico $\mathrm{Su}$ registrado obteve-se como potencialmente bom, e a densidade a granel satisfatória.

\section{Referências}

AMARO, N. C. S., COSTA, K., ÁlVARES, R., \& RODRIGUES, J. A Dinâmica de Exportação do Açaí em Oeiras do Pará-PA. XVIII ENCONTRO NACIONAL DE GEÓGRAFOS. São Luís, p. 1-10, 2016.

ASAI, H.; SAMSON, B.K.; STEPHAN, H.M.; SONGYIKHANGSUTHOR, K.; HOMMA, K.; KIYONO, Y.; IOUE, Y.; SHIRAIWA, T.; HORIE, T. Biochar amendment techniques for upland rice production in northern laos 1. SOIL PHYSICAL PROPERTIES, LEAF SPAD AND GRAIN YIELD. Field Crops Research, v. 111, N (1-2), p. 81-84, 2009.

BRAHAN, W. K. (2002), Combustibilidad de la madera: la experiência com espécies colombianas. 1. Bogotá: Fondo de Publicaciones, p50.

BRASIL. Ministério de Minas e Energia. Balanço energético nacional. Brasília, 2010. BRITO, J. O., BARRICHELO, L. E. G., SEIXAS, F., MIGLIORINI, A. J., \& MURAMOTO, M. C. Análise da produção energética e de carvão vegetal de espécies de eucalipto. IPEF, Piracicaba, v. 23, p. 53-56, 1983.

GOMES, P.A. \& OLIVEIRA, J.B. de Teoria da carbonização da madeira. In: FUNDAÇÃO CENTRO TECNOLÓGICA DE MINAS GERAIS - Uso da madeira para fins energéticos. Belo Horizonte, 2015. p.27-41.

Instituto Brasileiro de Geografia e Estatística (IBGE). Disponível em: < https://ibge.gov.br/> Acesso em: 22 de julho de 2019. 
ROSA, R.A.; ARANTES, M.D.C.; PAES, J.B.; ANDRADE, W.S.P.; MOULIN, J.C. Qualidade do carvão vegetal para o consumo doméstico. Journal of Biotechnology.

SÃO PAULO: Secretaria de Agricultura e Abastecimento. Resolução no 40 SAA, de 14 de dezembro de 2015.

SOARES, T. S., CARNEIRO, A. D. C. O., GONÇALVES, E. D. O., \& LELLES, J. D. Uso da biomassa florestal na geração de energia. Revista Científica Eletrônica de Engenharia Florestal, v. 8, p. 1-9, 2006.

STEINER, C.; BLUM, W.E.H.; ZECH, W.; DE MACEDO, J.L.V.; TEIXEIRA, W.G.; LEHMANN, J.; NEHLS, T. Long term effects of manure, charcoal and mineral fertilization on crop production and fertility on a highly weathered Central Amazonian upland soil. Plant Soil. v. 291, p. 275-290, 2007.

VERÍSSIMO, A.; PEREIRA, D. Produção na Amazônia Florestal: características, desafios e oportunidades. Parcerias Estratégicas, v. 19, n. 38, p. 13-44, 2015. 